5. Rabinovitch A (1998) An update on cytokines in the pathogenesis of insulin-dependent diabetes mellitus Diabetes Metab Rev 14: 129-151

6. Amrani A, Verdaguer J, Thiessen S, Bou S, Santamaria P (2000) IL-1alpha, IL-1beta, and IFN-gamma mark beta cells for Fas-dependent destruction by diabetogenic CD4( + ) T lymphocytes. J Clin Invest 105: 459-468
7. Like A, Rossini A (1976) Streptozotocin-induced pancreatic insulitis: new model of diabetes mellitus. Science 193: 415-417

Corresponding author: MA Myers, Department of Biochemistry and Molecular Biology, Monash University, Wellington Road, Clayton, Victoria, 3800, Australia, E-mail: Mark. Myers@med.monash.edu.au

\section{G972R polymorphism of IRS-1 in women with polycystic ovary syndrome}

To the Editor: Studies have reported a link between insulin resistance and polycystic ovary syndrome, one of the most common endocrine disorders of premenopausal women, characterized by anovulation and hyperandrogenism. Insulin resistance with increased risk of Type II (non-insulin-dependent) diabetes mellitus is a common comorbidity in patients with polycystic ovary syndrome which involves a post-binding defect in insulin receptor signalling [1]. In at least $50 \%$ of the women with polycystic ovary syndrome, insulin resistance could be related to reduced tyrosine kinase activity and excessive serine phosphorylation of the insulin receptor [2]. In the other $50 \%$, the pathogenesis of insulin resistance is still not known.

Insulin receptor substrate (IRS)-1 is the major cytoplasmic substrate of the insulin receptor. Many polymorphisms have been described in IRS-1, the most common aminoacid change being a glycine to arginine substitution at codon 972 (G972R) [3], which has an overall frequency of $5.8 \%$ in the general population and is the most common variant observed in Type II diabetes [4]. Transfection studies indicate that this variant could impair insulin-stimulated signalling, especially along the phosphatidylinositol 3-kinase pathway which controls glucose transport [5]. In human beings, this genetic variant is associated with reduced insulin sensitivity and with obesity and body fat distribution $[6,7]$.

We therefore examined the association between IRS-1 G972Arg genotype and PCOS and the metabolic characteristics of overweight (BMI $\geq 25 \mathrm{~kg} / \mathrm{m}^{2}$ ) (WHO criteria) and normal weight $\left(\mathrm{BMI}<24.9 \mathrm{~kg} / \mathrm{m}^{2}\right.$ ) polycystic ovary syndrome patients who were carriers of codon-972 variant (PCOS carriers). In 82 PCOS patients ( 23 normal weight and 59 overweight) and in 70 normal women (21 normal weight and 49 overweight), G972R genotypes were obtained by PCR amplification and BstN-1 restriction enzyme digestion [7]. An OGTT was done in all patients. Serum glucose and insulin were measured before the glucose load and 60 and 120 min after. Ho- meostasis model assessment for insulin-resistance $\left(\mathrm{HOMA}_{\mathrm{IR}}\right)$ and whole-body insulin sensitivity (ISI composite) were calculated [8]. Glucose was determined by the glucose oxidase method and insulin was assayed by RIA (DPC, Los Angeles, Calif., USA). All patients had given their written consent to their participation in the study which was approved by the local ethics committee. Statistical analysis was performed using chi square $\left(\chi^{2}\right)$ and Mann-Whitney tests. Differences were considered significant at $p<0.05$.

The frequency of $G 972 R$ variant (0.121) was higher $(p<0.02)$ in PCOS patients compared to normal women $(0.055)$.

Post-stimulated 2-h insulin was higher in PCOS carriers of codon-972 than in those without the mutation (Table 1). Among the PCOS carriers, six were overweight and four had normal weight. When normal weight and overweight carriers were compared to normal weight $[97.6(17.3 ; 176.7)$ vs 72.2 $(9.4 ; 251.8) \mu \mathrm{UI} / \mathrm{ml}]$ and overweight [178.(140.8;268.7) vs 97.2 $(25.1 ; 296.1) \mu \mathrm{UI} / \mathrm{ml}]$ patients without this mutation, post-stimulated 2-h insulin remained higher in the PCOS carriers. HO$\mathrm{MA}_{\mathrm{IR}}$ and ISI composite in normal weight and overweight PCOS carriers were 1.97 vs $6.03(p=0.038)$ and 4.41 vs 1.71 $(p=0.020)$, respectively.

These data suggest that the frequency of the heterozygote form of codon -972 variant is higher in PCOS patients than in normal women. Differences in $\mathrm{HOMA}_{\mathrm{IR}}$ and ISI composite between normal weight and overweight carriers, indicate that this IRS-1 variant interacts with obesity to influence insulin resistance, with little effect if the weight is normal, as previously suggested [7].

Acknowledgements. This work was supported by a grant from Fondecyt (1000973) and by the Alexander von Humboldt Foundation.

T.Sir-Petermann, F.Pérez-Bravo, B. Angel, M. Maliqueo, M. Calvillan, A. Palomino

Table 1. Metabolic parameters in PCOS patients according to the $G 972 R$ variant $^{\mathrm{a}}$

\begin{tabular}{llllll}
\hline & Insulin $(\mu \mathrm{UI} / \mathrm{ml})$ & & & & \\
& Fasting & $60 \mathrm{~min}$ & $120 \mathrm{~min}$ & HOMA $_{\text {IR }}$ & ISI composite \\
\hline PCOS (Gly/Gly) & 20.56 & 102.89 & 85.95 & 4.31 & 2.58 \\
$(n=72)$ & $(4.1-53.7)$ & $(28.8-355.4)$ & $(9.4-296.1)$ & $(0.6-13.6)$ & $(1.05-18.89)$ \\
PCOS (Gly/Arg) & 19.88 & 173.35 & 166.30 & 4.66 & 2.16 \\
$(n=10)$ & $(3.74-41.2)$ & $(60.2-269.0)$ & $(17.3-268.7)^{*}$ & $(0.7-9.0)$ & $(1.34-8.98)$ \\
\hline
\end{tabular}

$* p<0.05$ between PCOS(Gly/Gly) v/s PCOS(Gly/Arg)

${ }^{\mathrm{a}}$ Values are median and range 


\section{References}

1. Legro RS, Kunselman AR, Dodson WC, Dunaif A (1999) Prevalence and predictors. J Clin Endocrinol Metab 84: 165-169

2. Dunaif A, Xia J, Book CB, Schenker E, Tang Z (1995) Excessive insulin receptor serine phosphorylation in cultured fibroblast and in skeletal muscle. A potential mechanism for insulin resistance in the polycystic ovary syndrome. J Clin Invest 96: 801-810

3. Imai Y, Fusco A, Suzuki Y et al. (1994) Variant Sequences of insulin receptor substrate-1 in patients with noninsulindependent diabetes mellitus. J Clin Endocrinol Metab 79: $1655-1658$

4. Hitman GA, Hawrami K, McCarthy MI et al. (1995) Insulin receptor substrate-1 gene mutation in NIDDM: implications for the study of polygenic disease. Diabetologia 38: 481-486

5. Almind K, Inone G, Pedersen O, Kahn CR (1996) A common amino acid polymorphism in insulin receptor sub- strate-1 causes impaired insulin signaling. Evidence from transfection studies. J Clin Invest 97: 2569-2575

6. Clausen JO, Hansen T, Bjorbaek C, Echwald SM et al. (1995) Insulin resistance: interactions between obesity and a common variant of insulin receptor substrate-1. Lancet 346: 397-402

7. Baroni MG, Arca M, Sentinelli F et al. (2001) The G972R variant of the insulin receptor substrate-1 (IRS-1) gene, body fat distribution and insulin-resistance. Diabetologia 44: 367-372

8. Matsuda M, DeFronzo R (1999) Insulin sensitivity indices obtained from oral glucose tolerance testing. Diabetes Care 22: 1462-1470

Corresponding author: Prof. T. Sir-Petermann, Laboratory of Endocrinology, Dept of Medicine W. Division, School of Medicine, P.O.Box 33052, Correo 33. Santiago, Chile, E-mail: tsir@entelchile.net 